\title{
Salivary Gland Neoplasms in Indian Paediatric Population Visiting a Dental Institution
}

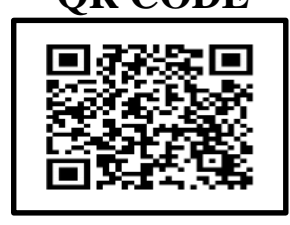

JYOTI M BIRADAR*1, GAYITHRI H KULKARNI², HARISH SHRINIVAS KULKARNI³, SUDHA SHIDAGAUDA PATIL4 ${ }^{4}$ ASHISH SHRIKANT SATAPUTE4, LAXMIKANT MAHADEV GHATNATTI5

INTRODUCTION: With a probability of 50\% malignancy, salivary gland tumors are not too commonly noticed in children and adolescents. Most of these have idiopathic etiology but a few pre-disposing factors have been reported in literature. We hereby report eighteen cases of paediatric salivary gland tumors in a study conducted from September 2013 to August 2018 at department of Oral and maxillofacial surgery at Tatyasaheb Kore Dental college and Research Centre, Kohlapur, Maharashtra, India.

AIM \& OBJECTIVES: This study aimed to inspect the distribution, clinical and histopathological features of salivary gland tumours in children and adolescents.

MATERIAL AND METHODS: A total of 18 cases of salivary gland tumors encountered in paediatric age group were studied and explored for age, gender, site proneness and for histopathological nature.

RESULTS: Female gender had a predominance over males. Parotid tumors were more common (77.78\%) as compared to tumors of submandibular glands. Six cases were diagnosed with benign tumors (pleomorphic adenoma) and rest had malignant tumors (mucoepidermoid in nature). Majority of the cases did not report undergoing any prior treatment.

CONCLUSION Present study revealed that salivary gland tumors in paediatric age group are quite rare with female gender being more prone. With majority of cases being mucoepidermoid in nature, parotid gland is most commonly affected.

KEYWORDS: Salivary Gland Tumors, Pleomorphic Adenoma, Mucoepidermoid Carcinoma.

\section{INTRODUCTION}

Neoplasms of salivary gland origin are not too common in younger age group of less than 18 years., The morphogenesis of salivary gland neoplasms stands controversial, but those with epithelial origin are exceedingly rare till adolescent age.3,4 In children, excluding vascular neoplasms, the percentage of malignant salivary gland tumors is approximately around 50\%.5-6

In different geographical regions, the prevalence of these salivary gland tumors varies in different age groups, gender and location..$^{7-8}$ Although most of the salivary gland tumors have no clear cut etiology and are idiopathic in nature with no association with the epidemiological variation in the global distribution, some precipitating factors like dietary regimen, race, occupation and Epstein Barr virus infection have been suggested. $9^{-11}$

The literature information available indicates that salivary gland tumours in children vary with respect to types of tumor histology and when compared to adult age group, their probability to develop malignant tumours is also high. Clinical and histopathological research on these tumors has been effected by their uncommonness, variable clinical aspects and an extensive range of morphologic presentations, making their histologic categorisation troublesome as some subjects report with asymptomatic slow extending tumors and others suffer with delayed recurrence. ${ }^{12-13}$

Tumors of the salivary glands may be located in the parotid, submandibular, sublingual, or other minor glands with parotid gland being the most commonly involved site, accounting for approximately 79 to $85 \%$ of cases. ${ }^{14^{-15}}$ These are very rare malignancies in children and have been treated with surgery, chemotherapy, and radiotherapy. The main focus of this study was to inspect the clinical and histopathological characteristics, tumour location and gender proneness of salivary gland tumours in paediatric patients.

\section{MATERIALS AND METHOD}

Present study was a five year retrospective study of 
all the salivary gland tumours received in paediatric age group during the period September 2013 to August 2018 at department of Oral and maxillofacial surgery at Tatyasaheb Kore Dental college and Research Centre, Kohlapur, Maharashtra, India. The clinical charts of all study subjects were thoroughly reviewed for age, sex, location of the tumor, and clinical characteristics. Details of the patients were obtained from the records pertaining to information regarding investigations done and presenting complaints along with signs and symptoms, tumor location, histopathological aspects and recurrences. The classification of all the cases was done as per the modified World Health Organization histologic classification of salivary gland tumors. ${ }^{13}$

Information regarding surgical procedures, radiotherapy and chemotherapy were available for those patients who had received these treatment modalities, before they were referred to our centre from some other hospital or institution. Fixation of all biopsy specimens was done using $10 \%$ formalin, followed by further processing into paraffin embedded sections and staining them with hematoxylin and eosin stain. The exclusion criteria included cases with mesenchymal tumors or lymphoproliferative lesions and those with incomplete records. Also was excluded a 14 year old male due to a secondary tumor in parotid gland.

\section{RESULTS}

The ages ranged from 7-16 years, with female predominance. Bilateral involvement was not noticed even in a single case. A total of 18 pediatric tumors were diagnosed out of which 6 were benign and 12 were malignant. The most common tumor was mucoepidermoid carcinoma (66.67\%). Site distribution was 14 cases in parotid gland (77.78\%), 4 cases in the submandibular gland $(\mathbf{2 2 . 2 2} \%)$ (Figure 1) and no tumor in any other salivary gland. Table 1 shows the demographic details of the study subjects along with clinical characteristics of the tumors.

Out of the total subjects, 12 were females. The tumor size ranged from 0.9 to 4.1 centimetres. Ten subjects had not undergone any kind of treatment in the past. Only surgery was performed in 4 subjects. Four patients had ongoing chemotherapy, two had a previous surgery and other two were prescribed radiotherapy. Chemotherapy protocol in these four subjects consisted of Cisplatin, Etoposide and Bleomycin. Fine needle aspiration cytology was

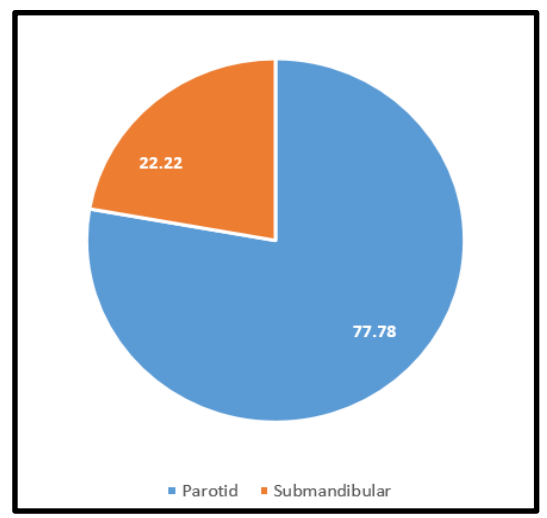

Figure 1. Demographic Details of The Study Subjects Along With Clinical Characteristics Of The Tumors.

done in all the cases. Fortunately all the subjects of our study were alive but with disease at the time of last follow up.

\section{DISCUSSION}

Salivary gland neoplasms are uncommon in children. The mean age of pediatric patients with these tumors has been reported to be 13.4 years, with a slight female preponderence. ${ }^{16}$ In our study, the mean age was 10.67 years. There were only eighteen cases reported in 5 years, which is consistent with the scarce occurrence of these tumors in children. No relevant information about the etiological factors was available for our subjects. Less males were affected than females. A total of 18 patients with paediatric salivary gland tumours were received in the 5 year study period at our study setting. A painless mass was the most common presenting symptom in all the cases. Incidence of benign salivary gland tumors was less as compared to malignant tumors which is not in accordance with a few literature reports. ${ }^{17-19}$ Guzzo et al. reported that the most common sites are the parotid, submandibular, and sublingual glands. ${ }^{20}$

In the present study the male to female ratio was 1:2, similar to previous data from Castro et al. ${ }^{5}$ and Seifert et al. ${ }^{21}$ and confirms in the pediatric group the well-known predominance of the salivary gland tumors for the female sex. This was also in line with other studies ${ }^{22,23}$ excepting for one study by Shafkat et al. ${ }^{17}$ which showed that had males have more tendency to develop salivary gland tumors.

Pleomorphic adenoma and the mucoepidermoid carcinoma were the only two histologic types that were recorded in compilations of intraoral salivary 


\begin{tabular}{|c|c|c|c|c|c|c|}
\hline S.No & Age/Gender & Gland & Location & Benign/Malignant & $\begin{array}{l}\text { Size } \\
\text { (centimetres) }\end{array}$ & $\begin{array}{l}\text { Previous } \\
\text { treatment }\end{array}$ \\
\hline$\overline{1}$ & 12/Female & Parotid & Right parotid & Benign & 3.1 & No treatment \\
\hline 2 & 9/Male & Parotid & Right parotid & Benign & 1.5 & Surgery \\
\hline 3 & 7/Female & Submandibular & $\begin{array}{l}\text { Right } \\
\text { submandibular }\end{array}$ & Malignant & 0.9 & No treatment \\
\hline 4 & 9/Female & Parotid & Right parotid & Malignant & 1.8 & No treatment \\
\hline 5 & 11/Female & Parotid & Left parotid & Benign & 3.2 & $\begin{array}{l}\text { Radiotherapy, } \\
\text { Chemotherapy }\end{array}$ \\
\hline 6 & 14/Male & Parotid & Right parotid & Malignant & $4 \cdot 1$ & $\begin{array}{l}\text { Surgery, } \\
\text { Chemotherapy }\end{array}$ \\
\hline 7 & 16/Female & Parotid & Left parotid & Malignant & 3.6 & No treatment \\
\hline 8 & 10/Female & Submandibular & $\begin{array}{l}\text { Left } \\
\text { submandibular }\end{array}$ & Malignant & 2.6 & Surgery \\
\hline 9 & 8/Male & Parotid & Right parotid & Malignant & 2.9 & No treatment \\
\hline 10 & 9/Male & Parotid & Right parotid & Malignant & 2.8 & No treatment \\
\hline 11 & 9/Female & Submandibular & $\begin{array}{l}\text { Left } \\
\text { submandibular }\end{array}$ & Malignant & 2.4 & Surgery \\
\hline 12 & 16/Female & Parotid & Left parotid & Malignant & $3 \cdot 3$ & No treatment \\
\hline 13 & 13/Female & Parotid & Right parotid & Malignant & 2.0 & No treatment \\
\hline 14 & 12/Female & Parotid & Left parotid & Benign & 2.9 & $\begin{array}{l}\text { Radiotherapy, } \\
\text { Chemotherapy }\end{array}$ \\
\hline 15 & 15/Male & Parotid & Right parotid & Malignant & $3 \cdot 9$ & $\begin{array}{l}\text { Surgery, } \\
\text { Chemotherapy }\end{array}$ \\
\hline 16 & 11/Female & Parotid & Right parotid & Benign & 2.8 & No treatment \\
\hline 17 & 8/Male & Parotid & Right parotid & Benign & 1.7 & Surgery \\
\hline 18 & 8/Female & Submandibular & $\begin{array}{l}\text { Right } \\
\text { submandibular }\end{array}$ & Malignant & 1.1 & No treatment \\
\hline
\end{tabular}

Table 1. Clinical Characteristics of the Patients with Salivary Gland Tumor.

gland tumors in the pediatric group in our study. The most common salivary gland tumor in our study was Mucoepidermoid carcinoma occuring predominantly in parotid gland which correlates with data from studies by Pinkston and $\mathrm{Cole}^{24}$, Poomsawat $\mathrm{S}$ et al..$^{25}$ and Ito FA et al. ${ }^{26}$ The ratio of pleomorphic adenoma to mucoepidermoid carcinoma from our study results are dissimilar to that reported by Waldron et al. ${ }^{27}$ and Krolls et al. ${ }^{3}$ who confirmed the same to be 10:1. In our study, the parotid gland was the most common site at $77.78 \%$, followed by the submandibular gland. It has been described by Shikhani and Johns that the higher the level of the gland, higher is the incidence of malignancies. ${ }^{28}$

Tumor size ranged from 0.9 to 4.1 centimetres which is in accordance with the study by Wallace et al. ${ }^{22}$ In a study by Ribeiro Kde $\mathrm{C}$ et al, tumor size was reported to range from 0.7 to 8.5. Histopathological diagnosis given on light microscopy, correlated well with FNAC and Ultrasound findings in almost all cases.

Overall, salivary gland malignant epithelial tumors in children usually have a good prognosis. Five years overall survival rate ranges from $81 \%^{30}$ to $100 \%$ in the series reported by Ethunandan. ${ }^{31}$ Survival was decreased dramatically in the series reported by Baker. ${ }^{32}$ We hypothesise that the general good prognosis in children is probably due to the low number of high-grade tumors. All our study subjects were alive with disease during the last follow up.

\section{CONCLUSION}

Our research confirms the rarity of salivary gland neoplasms in the pediatric age group. The most common tumor in the present study was mucoepidermoid carcinoma and parotid gland was the most common site of involvement with female preponderance. Londitudinal multicentric long term studies need to be conducted to expose more 
predisposing factors and etiological causes for early detection to improve prognosis and prevention of these rare tumors. This would also aid in describing the incidence of recurrence of salivary gland neoplasms helping the healthcare professionals to plan and select treatment options for individual cases.

\section{REFERENCES}

1. Lingen MW, Kumar V. Salivary glands. In: Kuamr V, Abbas AK, Fausto N. Robbin, Cotran, editors. Pathologic basis of disease.7th edition, Philadelphia:Elsevier Saunders; 2005, p.790-4.

2. Ellis GL.A uclair PL. Tumours of the salivary glands: Atlas of tumour pathology, 3rd series, fascicle 17, Wasington DC: AFIP; 1996, p. 3-10.

3. Krolls SO, Trodahl JN, Boyers RC. Salivary gland lesions in children: A survey of 430 cases. Cancer 1972;30:459-69.

4. Pons - Vicente O, Almendros-Marques N, BeriniAytes L, Gay Escoda C. Minor salivary gland tumors: A clinicopathological study of 18 cases. Med Oral Pathol Oral Cir Bucal., 2008; 13: 582-8.

5. Castro ELB, Huvos AG, Strong EW, et al. Tumors of the major salivary glands in children. Cancer 1972;29:312-7.

6. Ethmundan M, Davies B, Pratt CA, Puxeddu R, Brennan PA. Primary epithelial submandibular salivary gland tumors - Review of management in a district general hospital setting. Oral Oncol., 2009; 45: $173-6$.

7. Ma'aita JK, Al-Kaisi N, Al-Tamimi S, Wraikat A. Salivary gland tumors in Jordan: A retrospective study of 221 patients. Croat Med J., 1999; 40: 539- 42. 8. Jaber MA. Intraoral minor salivary gland tumors: A review of 75 cases in a Libyan population. Int J Oral Maxillofac Surg., 2006; 35: 150-4.

9. Speight PM, Barret AW. Salivary Gland Tumours. ORAL Diseases, 2002; 8: 229- 40.

10. Pinkston JA, Cole P. Cigarette smoking and Wargthins Tumour. Am J Epidemiol., 1999; 144: 1837.

11. El-Ghazayerli MM, Abdel Aziz AS. Salivary Gland Tumours in Egypt and non-Western countries. Br J Cancer, 1964; 18: 649-54.

12. Thackray AC, Sobin LH. Histological typing of salivary gland tumors. Geneva: World Health Organization, 1972.

13. Seifert G, Brocheriou C, Cardesa A, Eveson JW. WHO inter- national histological classification of tumors. Pathol Res Pract 1990;186:555-81.
14. Guzzo M, Locati LD, Prott FJ,et al. Major and minor salivary gland tumors. Crit Rev Oncol Hematol. 2010;74(2):134-48.

15. Shikhani AH, Johns ME. Tumors of the major salivary glands in children. Head Neck Surg. 1988;10(4):257-63.

16. Fonseca I, Martins AG, Soares J. Epithelial salivary gland tumors of children and adolescents in southern Portugal. A clinicopathologic study of twenty-four cases. Oral Surg Oral Med Oral Pathol. 1991;72(6):696-701.

17. Shafkat Ahmed, Mohainmad Lateef, Rouf Ahmad. JK-Practitioner, 2002; 9(4): 231-233.

18. Ogata H, Ebihara S, Mukai K. Salivary gland neoplasms in children. Jpn J Clin Oncol., 1994; 24(2): 88-93.

19. Laikui L, Hongwei L, Hongbing J, Zhixiu H. Epithelial salivary gland tumors of children and adolescents in west China population: a clinicopathologic study of 79 cases. J Oral Pathol Med., 2008; 37(4): 201-5.

20. Guzzo M, Ferrari A, Marcon I,et al. Salivary gland neoplasms in children: the experience of the Istituto Nazionale Tumori of Milan. Pediatr Blood Cancer.2006;47(6):806-10.

21. Seifert G, Okabe H, Caselitz J. Epithelial salivary gland tumors in children and adolescents: analysis of 8o cases J Otorhinolaryngol Relat Spec 1986;3:137. 22. Waalace AC, Mac Dougall LT, Hides JA, Lederman JM. Salivary gland tumours in Canadian Eskimos. Cancer 1963; 16(10): 1338-52.

23. Davies JNP, Dodge OG, Burkitt DP. Salivary gland tumours in UGANDA. Cancer 1963; 17(10): 1338-52.

24. Pinkston JA, Cole P. Incidence rates of salivary gland tumours - A population based study. Otolaryngol Head Neck Surg., 1999; 120: 834-40.

25. Poomsawat S, Punyasingh J, Weerapradist W. A retrospective study of 60 cases salivary gland tumours in Thai population. Quintessence Int., 2004; 35 : 577-81.

26. Ito FA, Ito K, Vargas PA, de Almeida OP, Lopes MA. Salivary gland tumours in a Brazilian population. A retrospective study of 496 cases. Int J Oral Maxillofac Surg., 2005; 34: 533-6.

27. Waldron CA, EI-Mofty SK, Gnepp DR. Tumors of the intraoral minor salivary glands: a demographic and histologic study of 426 cases. Oral Surg Oral Med Oral Pathol 1988;66:323-33.

28. Shikhani AH, Johns ME. Tumors of the major salivary glands in children. Head Neck Surg 1988;10:257-63. 
29. Ribeiro Kde C, Kowalski LP, Saba LM, deCamargo B. Epithelial salivary glands neoplasms in children and adolescents: a forty-four-year experience. Med Pediatr Oncol.2002;39(6):594-6oo. 30. De Cassia Braga Ribeiro K, Kowalski LP, Buazar Saba LM, et al. Epithelial salivary glands neoplasms in children and adolescent: A forty-four-year experience. Med Pediatr Oncol 2002;39:594-6oo.
31. Ethunandan M, Ethunandan A, MacPherson D, et al. Parotid neoplasms in children: Experience of diagnosis and management in a district general hospital. Int J Oral Maxillofac Surg 2003;32:373- 377. 32. Baker SR, Malone B. Salivary gland malignancies in children. Cancer 1985;55:1730-6.

Source of support: Nil, Conflict of interest: None declared

Cite this article as:

Biradar JM, Kulkarni GH, Kulkarni HS, Patil SS, Satapute AS, Ghatnatti LM. Salivary Gland Neoplasms in Indian Paediatric Population Visiting a Dental Institution. Int Healthc Res J. 2019;2(12):316-320. doi: 10.26440/IHRJ/0212.03.521062

\section{AUTHOR AFFILIATIONS:}

1. ${ }^{*}$ Associate Professor, Department of Oral and Maxillofacial Surgery (Corresponding Author)

2. Professor and Head, Department of Oral and Maxillofacial Surgery

3. Principal

4. Assistant professor (Lecturer), Department of Oral and Maxillofacial Surgery

5. Assistant professor (Lecturer), Department of Oral and Maxillofacial Surgery

Department of Oral and Maxillofacial Surgery

Tatyasaheb Kore Dental College and Research Centre, New Paragaon -416113

6. MDS, Department of Orthodontics, Ghattanatti Orthodontic and Orthopedic Centre, Tal- Miraj, District- Sangli, Maharashtra.

For article enquiry/author contact details, e-mail at: editor.ihrj@gmail.com, editor@ihrjournal.com 